\title{
Methodology for bioassay entomopathogenic Bacillus against sand fly (Diptera, Psychodidae, Phlebotominae) larvae
}

\author{
Eduardo Dias Wermelinger ${ }^{1,2}$ \\ José Cola Zanuncio ${ }^{2}$ \\ Elizabeth F. Rangel ${ }^{1}$ \\ Paulo R. Cecon ${ }^{3}$ \\ Leon Rabinovitch ${ }^{4}$
}

\begin{abstract}
The objective of this research is to present a method to bioassay entomopathogenic Bacillus species against sand fly (Diptera, Psychodidae, Phlebotominae) larvae. The vector Lutzomyia longipalpis (Lutz \& Neiva, 1912) (Diptera, Psychodidae, Phlebotominae) and some Bacillus strains were used in laboratory to develop this method. Some characteristics of this method are commented and the importance to develop a standard method to test pathogenicity of Bacillus species against phlebotomine larvae is also discussed.

KEY WORDS. Phlebotominae, Bacillus, bioassay, method
\end{abstract}

Due to the importance of phlebotomine species (Diptera, Psychodidae, Phlebotominae) as vectors of leishmaniasis, it is necessary to investigate strategies to be used in their control, especially against their immature stages. Bacterial species of the genus Bacillus have been used as an alternative control method for some Diptera of medical importance and the possibilities of using these enthomopathogenic agents against phlebotomine vectors were discussed (WARBURG 1991; WARBURG et al. 1991; Oliveira Filho \& Melo 1994; PENER \& WilamowsKi 1996; RoBerT et al. 1997). However, few studies have been done aiming to observe the pathogenic activity of Bacillus species to phlebotomine larvae (BARJAC et al. 1981; WERMELINGER et al. 1995a; Pener \& Wilamowski 1996; Wermelinger et al. in press). Since it is difficult to compare results of bioassays which used different methodologies, it is important to develop and present techniques that could allow possible comparisons between such tests. Considering that no bioassay method with Bacillus for phlebotomine larvae has been described with details, the aim of this research is to present a methodology to bioassay entomopathogenic Bacillus against larvae of these insects.

1) Departamento de Entomologia, Instituto Oswaldo Cruz. 21045-900 Rio de Janeiro, Rio de Janejro, Brasil.

2) Departamento de Biologia Animal, Universidade Federal de Viçosa. 36571-000 Viçosa, Minas Gerais, Brasil. E-mail: zanuncio@mail.ufv.br

3) Departamento de Informática, Universidade Federal de Viçosa. 36571-000 Viçosa, Minas Gerais, Brasil.

4) Departamento de Bacteriologia, Instituto Osvaldo Cruz. Caixa Postal 926, 21045-900 Rio de Janeiro, Rio de Janeiro, Brasil. 
The technique was developed with Lutzomyia longipalpis (Lutz \& Neiva, 1912) (Diptera, Psychodidae, Phlebotominae), the vector of the American visceral leishmaniasis, obtained from a phlebotomine insectary of the laboratory in the Department of Entomology of the Oswaldo Cruz Institute (IOC) and with bacterial strains of Bacillus thuringiensis serovar israelensis (B.t.i.), Bacillus sphaericus, and Bacillus thuringiensis serovar morrisoni from the Department of Bacteriology of the same Institute, in Rio de Janeiro, State of Rio de Janeiro, Brazil. The results of these tests are presented in WERMELINGER et al. (1995a in press). L. longipalpis larvae was fed with industrialized food for aquarium fish (Vitormonio $\mathbb{R}$ ) which has been used in insectary to rear L. longipalpis and Lutzomyia intermedia (Lutz \& Neiva, 1912) (Psychodidae, Phlebotominae) (RANGEL et al. 1985). This technique consists of groups of 20 young third instar larvae of L. longipalpis, selected by size (around $1 \mathrm{~mm}$ ) and placed into Petri dish plates (150 mm by $20 \mathrm{~mm}$ ), previously sterilized, each one representing one experimental unit. Each plate contained in its bottom a layer of Paris plaster approximately 5 to $10 \mathrm{~mm}$ thick, humidified with distilled water aiming to maintain the humidity above $90 \%$ within them. These Petri dishes were individualized in aseptic plastic pots, with $170 \mathrm{~mm}$ diameter and $70 \mathrm{~mm}$ height, lined with sterile paper filter, also humidified.

Second instar larvae of L. longipalpis were previously maintained in Petri dishes in similar conditions as the bioassay for adaptation before being used. At the beginning of the third stadium, larvae of L. longipalpis were placed in sterile Petri dishes with each one of them as one experimental unit. Depending on the test each one of them can have different number of replications and concentrations of the products. For example, WERMELINGER et al. (1995a) used three replications and eight concentrations and WERMELINGER et al. (in press) used at least four repetitions and two concentrations.

The inoculum must be quantified, mixed and homogenized with larval food before being used for larvae in treated groups. The concentrations of such inoculum are formed using biomass ( $\mathrm{mg}$ of dry weight) bearing delta-endotoxin crystals and spores of Bacillus, obtained by bacterial growth in a New Brunswick 14 liter capacity fermentator loaded with soya flour, divalent metals and yeast extract liquid culture medium, during 22 hours at $33^{\circ} \mathrm{C}$, and harvested with continuous centrifugation ( 3500 $\mathrm{rpm}$ ). The biomass material is weighed within an Eppendorf and suspended in $0.5 \mathrm{ml}$ distilled water, homogenized in vortex by 20 to 30 seconds and mixed with larval food $(1 \mathrm{~g})$, previously autoclaved at $120^{\circ} \mathrm{C}$ during 20 minutes and offered to sand fly larvae. After 48 hours all food not offered to larvae should be discarded. Larval food in the control lots is humidified with $0.5 \mathrm{ml}$ distilled water aiming to standardize its texture. The food with inoculum and that humidified of the control lots are offered to larvae during seven days and changed every 48 hours. After this period, a normal food (without inoculum) is offered to the groups of larvae of $L$. longipalpis until they reach the pupal stage. The percentage of mortality is calculated according to the number of pupae obtained. This is important because the duration of the larval cycle of $L$. longipalpis increases when larvae of this species are treated with B.t.i., according to the results of BARJAC et al. (1981) and WERMELINGER et al. (1995b). It seems that BARJAC et al. (1981) and PENER \& WilAMOSKI (1996) maintained larvae of $L$. 
longipalpis during its whole larval cycle feeding on food containing the inoculum. In this present method, the period of seven days of inoculum ingestion by L. longipalpis larvae proved to be enough to study susceptibility patterns of this vector to entomopathogenic Bacillus (WERMELINGER et al. 1995a,b, in press). For this reason the period of seven days of feeding in contaminated food should be used in testing enthomatogenic Bacillus against Diptera vectors.

ACKNOWLEDGEMENTS. To the staff of the Laboratory of Bacterial Physiology of the Department of Bacteriology and to the Sandfly Insectary, of the Leishmaniasis and Onchocerciasis Vector Laboratory, of the Department of Entomology of Oswaldo Cruz Institute for technical support. To CNPq and FAPEMIG for support.

\section{REFERENCES}

Barjac, H. DE; L. Larget \& R. Killick-Kendrick. 1981. Toxicité de Bacillus thuringiensis var. israelensis, sérotype H14, pour les larves de phlébotomes, vecteurs de leishmanioses. Bull. Soc. Pathol. Exot. 74: 485-489.

Oliveira Filho, A.M. \& M.T. Melo. 1994. The chemical control of vectors of leishmaniasis. Mem. Inst. Oswaldo Cruz 89: 461-462.

Pener, H. \& A. WILAmowski. 1996. Susceptibility of larvae of the sandfly Phlebotomus papatasi (Diptera: Psychodidae) to Bacillus sphaericus. Bull. Entomol. Res. 86: 173-175.

Rangel, E.F.; N.A. SouzA; E.D. Wermelinger \& A.F. BArbosa. 1985. Estabelecimento de colônia, em laboratório de Lutzomyia intermedia (Lutz \& Neiva, 1912) (Diptera, Psychodidae, Phlebotominae). Mem. Inst. Oswaldo Cruz 80: 219-226.

Robert, L.L.; M.J. Perich; Y. Schlein; R.L. Jacobson; R.A. Wirtz; P.G. Lawyer \& J.I. Githure. 1997. Phlebotomine sand fly control using bait-fed adults to carry the larvicide Bacillus sphaericus to the larval habitat. Jour. Amer. Mosq. Control Assoc. 13: 140-144.

WARBURG, A. 1991. Entomopathogens of phlebotomine sand flies: laboratory experiments and natural infections. Jour. Inv. Pathol. 58: 189-202.

Warburgi, A; K. Ostrovska; P.G. Lawyer. 1991. Pathogens of phlebotomine sandflies. A review. Parassitologia 33 (Suppl. 1): 519-526.

WeŔmelinger, E.D.; J.C. ZANUnCiO; E.F. Rangel \& L. Rabinovitch. 1995a. Toxic activity (LC50) of Bacillus thuringiensis subsp. israelensis strain LFB/FIOCRUZ 710 on Lutzomyia longipalpis (Diptera: Psychodidae: Phlebotominar). Amer. Jour. Trop. Med. Hyg. 53 (2): 163.

- 1995b. Observations about symptoms and signs on Lutzomyia longipalpis larvae (Lutz \& Neiva, 1912) (Diptera; Psychodidae, Phlebotominae) under bioassays with Bacillus thuringiensis subsp. israelensis strains LFB/FIOCRUZ 584 and LFB/FIOCRUZ 710. Mem. Inst. Oswaldo Cruz 90: 235 .

Wermelinger, E.D.; J.C. Zanuncio; E.F. Rangei; P.R. Cf.Con \& L. Rabinovitch. (in press). Toxicity of Bacillus species to larvae of Lutzomyia longipalpis (L. \& N.) (Diptera: Psychodidae: Phlebotominae) Anais Soc. Bras. Entomol..

Recebido em 19.VIII.1999; aceito em 25.VIII.2000. 